\title{
RISK MANAGEMENT FOR 4-H YOUTH DEVELOPMENT WORK
}

\section{Shooting Sports State Plan and Program Guidelines}

This is one publication in the series Risk Management for 4-H Youth Development Work. This series is intended to equip UF/IFAS Extension county faculty, staff, volunteers, and youth for the important task of providing best practices in risk management strategies.

Our goal is to conduct educational events and activities that coincide with the 4-H mission and mandates while protecting the safety of participants, sponsors, property, finances, and the goodwill/reputation of the 4-H name. The inherent risk of events and activities can be mitigated through planning and preparation. This risk management guide has been created to outline ways to prepare for and deal with the specific risks associated with your program.

Early planning is key to conducting successful events and activities. A helpful tool in this process is the Risk Management for 4-H Youth Development Work: Pre-Event Planning Guide and Matrix which is found within the Risk Management for 4-H Youth Development Work Series: http://edis.ifas.ufl.edu/topic_series_risk_management_ for_4-h_youth_development_work. As you work through this matrix, questions may arise that are unique to a specific situation and may not be completely answered by the series. Extension faculty and staff should refer these questions to appropriate personnel. Questions that require time for research punctuate the need for early planning.

Another tool is the Risk Management Checklist which can be used as a guide when planning an activity or event.

\section{Introduction: 4-H Shooting Sports Program}

The 4-H Shooting Sports Program should be viewed as a vehicle for achieving youth development, the mission of Extension 4-H youth programs. The 4-H Shooting Sports Program teaches young people the safe and responsible use of firearms, principles of archery, and hunting basics. Lifelong skill development is one of the main benefits of involvement in the 4-H Shooting Sports Program and applies to both youth and adults involved in the program. Specifically, the 4-H Shooting Sports Program is designed to:

- Provide youth proper training in the use of firearms, archery equipment, and other areas of shooting sports.

- Provide thorough instruction in shooting sports safety.

- Develop life skills such as self-confidence, personal discipline, responsibility, and sportsmanship.

- Create an appreciation and understanding of natural resources and their wise use.

- Provide volunteer instructors safe and proper instructional techniques.

- Show volunteer leaders how to plan and manage 4-H Shooting Sports Clubs.

The 4-H Shooting Sports Program is a national program with guidelines provided by the National 4-H Shooting Sports Committee. This committee is made up of Extension professionals, volunteers, and others. The committee plans, organizes, and conducts national and regional training programs to certify Level II Instructors (see definition below) in order that they might conduct shooting sports training programs. These Level II 
instructors are discipline-certified to provide instruction to Level I instructors within their respective states.

LEVEL I Instructor-Participants who successfully complete a state training conducted by a Level II instructor. Level I Instructors are discipline-certified to work directly with youth.

LEVEL II Instructor-Participants who successfully complete a National or Regional training conducted by the National Shooting Sports Committee. Level II Instructors are discipline certified to provide Level I instruction.

The Florida 4-H Shooting Sports Program follows the National 4-H Shooting Sports Program guidelines via the Florida State Shooting Sports Committee. The Florida State Shooting Sports Committee is comprised of Level II Instructors, Extension specialists, county faculty, and volunteers. This group is responsible for establishing guidelines specific to Florida, planning events, organizing and conducting Level I trainings, and developing educational recourses. The Florida State Shooting Sports Committee will also serve as an approval mechanism for any and all events, trainings, or resource development within the program. The 4-H Shooting Sports Program is an official 4-H program open to any individuals that qualify under current age policies (see below).

\section{Shooting Sports Training}

\section{Guidelines}

- All Florida State 4-H Shooting Sports Instructor Training (Level I) must be conducted by individuals who are Level II certified by the National 4-H Shooting Sports Program Committee.

- County, multi-county, or district Shooting Sports Program Level I trainings must be approved by the State Shooting Sports Committee and be conducted by a team (volunteers or agents) that have received proper Level II training from nationally trained instructors.

- All 4-H Shooting Sports programs conducted for youth must be conducted and supervised by those individuals that have successfully completed a Level I discipline training.
- All aspects of a training activity must be organized prior to the training (i.e., planning, announcing, conducting, evaluating). Responsibilities of county agents, volunteers, and state staff are to be outlined prior to the training event.

- Volunteer responsibilities include, but are not limited to, conducting activities, providing support, and assisting with shooting sports discipline training.

- The State Shooting Sports Committee will establish consistency in certification and recognition of participant completion of training programs.

\section{Certification/Training}

\section{Requirements}

State requirements for certification of volunteers at Level I for all disciplines involve a minimum of 15-20 hours of training in each of the discipline areas.

- Level I volunteer certification is determined by exam, homework, practicum, and instructor observation.

The discipline instructor reserves the right to withhold certification if the volunteer is found to lack effective instructional skills, knowledge, or safety practices or other concerns that may arise during the course of a training.

- The Level I certification period for all disciplines shall be three years from the date of the initial training. Active volunteers must submit participation information to their County 4-H program.

- A Level I Instructor can be recertified in a discipline by:

- Attending one (1) of the state Level I training programs offered.

- Teaching in the classroom and range at a state sponsored 4-H Shooting Sports event or camp under the supervision of a Level II Instructor.

- Attending an annual discipline update training meeting.

- Attending a State Shooting Sports Committeesanctioned regional volunteer training.

- Making arrangements with a Level 2 Instructor to observe a club or local event (this is dependent on the availability of the Level 2 Instructor). 
- Actively teaching youth in the discipline for two of the three years of the certification period (must be verified by the County $4-\mathrm{H}$ agent).

- Standard training evaluations will be established and implemented by the State Shooting Sports Committee

- Level 1 trainings will be conducted as needed. Typically, one state training is held yearly and is usually conducted at a designated 4-H camp. Regional trainings will be conducted as needed pending approval of the State Shooting Sports Committee (see Level 1 Training Request Form). Typically, a minimum of eight to ten participants in each discipline is required to conduct a regional training.

- All shooting sports training instructors (Level I and II) will conduct training that complies with established National Shooting Sports discipline; teaching guidelines provided during certification training.

- Junior Leaders must be 14 years old as of September

1. They must have completed Level I training and can only assist while a Level I Instructor is managing the shooting line. All other Level I Instructors must be 21 years old or older.

- All volunteers working with youth must comply with the University of Florida policies and guidelines for volunteer certification. This may include background checks, finger printing, and other registration procedures. Please consult with your local UF/IFAS Extension 4-H agent for details.

\section{Shooting Sports Events/Activities Guidelines}

- Insurance: As with any other UF 4-H Program activity, there is liability coverage/protection from the State of Florida for 4-H Shooting Sports events, activities, and club meetings. Information and certificates of coverage can be obtained from your county 4-H faculty/agent member. Please remember this is insurance against liability claims related to $4-\mathrm{H}$ programming and should cover volunteers, agents, and other UF employees directing a 4-H program.
This policy does not cover facilities/properties that are not directly owned by UF. The American Income Life (AIL) club insurance is a policy related to injuries that might occur during a 4-H event or other activities. The AIL insurance is an annual coverage available to $4-\mathrm{H}$ clubs through their counties. A special event insurance is also available from AIL. Contact the county 4-H faculty/agent for additional information.

- Age Requirements: Participation in the Florida 4-H Shooting Sports Program follows other State 4-H programs requiring participants to be eight (8) years old by September 1 of the program year. The exceptions to this rule are with the disciplines of shotgun, hunting, and muzzle loading, which are not entry level/age disciplines. Participation by 5-7 year olds in the Florida 4-H Shooting Sports Program follows the National Shooting Sports Program age policy in which 5-7 year olds are not allowed to participate.

Discipline specific ages are as follows:

- Small bore, air rifle and archery 8 years old by Sept 1. (Competition: Archery and air rifle 8 yrs.; Small bore (22cal) 11 yrs. by Sept. 1)

- Shotgun and hunting 10 years old by Sept. 1. (Competition: 11 yrs. by Sept. 1)

- Muzzle loading

12 years old by Sept. 1. (Competition: 12 yrs. by Sept. 1)

NOTE 1: Individual counties, at their discretion, may adopt a minimum age requirement that is older than the state guidelines, but in no cases may a county lower the minimum age requirement set forth in the State guidelines.

NOTE 2: Youth participants in the Hunting discipline can only participate in age-appropriate disciplines.

NOTE 3: Participants in the muzzle loading discipline must be 12 years old or older and have participated in the 4-H Shooting Sports rifle or shotgun program for 1 year. 
- Youth Events: All 4-H events through which 4-H members participate will follow rules and guidelines established by the State and/or National Shooting Sports Programs (see Florida 4-H State Rulebook and/or State Events Overview). Annual State and Regional events and matches will be planned and approved by the State Shooting Sports Committee.

Equipment Safety: All county shooting sports equipment should be routinely inspected for safety purposes. Private firearms/equipment used in 4- $\mathrm{H}$ activities and events should also be inspected prior to participation. The current shooting sports discipline instructor or his/her designee is responsible for equipment safety.

Risk Management Plan: All counties are required to have a risk management plan in place for all shooting sports activities. Contact the county 4-H faculty/agent for additional information.

\section{Guidelines for County 4-H Shooting Sports Program Equipment}

- Equipment includes: bows, arrows, firearms, targets, ammunition, and other shooting sports program equipment related to the disciplines of archery, hunting, muzzle loading, rifle, and shotgun. The county 4-H program is responsible for maintaining an inventory of equipment noting the location and disposition of all firearms and bows. All grantacquired equipment is the property of the county Extension program and as such must be inventoried for the purposes of accountability to the granting agency.

- Storage of 4-H Shooting Sports Program equipment, owned by the counties, is to be determined by the county in accordance with county policy and Florida State law. Florida State Law Sec. 790.174 requires that firearms be locked and/or stored in a secure manner to prevent minors from gaining access to them.

- Typical storage areas include, but are not limited to, county Extension offices, law enforcement offices, private residences, and other secure sites.
- Loan requests for "state" shooting sports equipment to support county shooting sports programs must be done 30 days in advance to the State Shooting Sports Committee through county 4-H offices and is dependent upon availability. Requests must contain names of instructors and the disciplines in which they are certified to teach. An inventory list of all equipment and shooting sports supplies must be completed prior to and upon completion of the training by the county $4-\mathrm{H}$ agent. Storage of this equipment will adhere to the guidelines stated above.

\section{Shooting Sports Educational Resources Guidelines}

- Shooting sports educational initiatives are to include: training, competitive events, camps, and discipline (shotgun, rifle, archery, hunting, and muzzle loading) specific curriculum.

- Shooting sports educational materials for statewide distribution are to be developed by the State Shooting Sports Committee.

- Shooting sports curriculum must be approved by the State Shooting Sports Committee before statewide distribution. 